\title{
Thrombocytopenia in plasmodium parasitized pregnant women in the Niger Delta of Nigeria
}

This article was published in the following Dove Press journal:

Pathology and Laboratory Medicine International

24 December 2009

Number of times this article has been viewed

\section{Orhabor' \\ Z A Jeremiah' \\ T C Adias ${ }^{2}$ \\ M L Hart' \\ 'Department of Medical Laboratory Sciences, College of Health Sciences, Niger Delta University, Wilberforce Island, Bayelsa State, Nigeria; ${ }^{2}$ Department of Medical Laboratory Sciences, Rivers State University of Science and Technology, Port Harcourt, Nigeria}

Correspondence: Erhabor Osaro Department of Blood Sciences, Royal Bolton Hospital Foundation NHS Trust, Bolton, Lancashire, UK

Tel +447932363217

Email n_osaro@yahoo.com
Background: Malaria infection during pregnancy is a major public health problem in tropical and subtropical regions of the world. Hematological changes associated with malaria in pregnancy are not well documented, and have focused predominantly on anemia. The aim of this study was to determine the impact of Plasmodium parasitaemia on the platelet count of pregnant women in the Niger Delta of Nigeria.

Methods: In this observational study we reviewed the platelet counts from routine complete blood count (CBC) in a cohort of healthy (pregnant and nonpregnant) and malaria-infected pregnant women attending antenatal clinics. A platelet count of $100 \times 10^{9} / \mathrm{L}$ was the threshold at two standard deviations below the mean for healthy Nigerian pregnant women used to indicate thrombocytopenia. Differences in platelet counts were compared based on malaria species and parasitemia in matched nonpregnant and pregnant women. Blood smears from Quantitative Buffy Coat malaria-positive samples stained with Giemsa were used for determination of parasite load and specie identification by light microscopy.

Study design: This case control study evaluated the effect of malaria parasitemia on the platelet count of 50 plasmodium parasitized pregnant subjects. Fifty nonmalaria parasitized pregnant women and fifty nonpregnant and nonmalaria-infected subjects served as control.

Results: The mean platelet counts $\left(\times 10^{9} / \mathrm{L}\right)$ were significantly lower in pregnant subjects with an episode of Plasmodium falciparum malaria $111.3 \pm 9.3 \times 10^{9} / \mathrm{L}$ compared to nonparasitized and healthy nonpregnant controls $\left(255.09 \pm 24.10\right.$ and $\left.270 \pm 51.5 \times 10^{9} / \mathrm{L}\right)$ respectively. Platelet count values were $112.5 \pm 9.68 \times 10^{9} / \mathrm{L}$ and $126.3 \pm 16.7 \times 10^{9} / \mathrm{L}$ for the primigravidae and multigravidae respectively. $\left(\chi^{2}=10.46 ; P=0.05\right)$. Parasite density was significantly higher among Plasmodium parasitized primigravidae compared to multigravidae $2150(1638-2662)$ parasites $/ \mu \mathrm{L}$ in primigravidae women compared to 1826 (1430-2222) parasites/ $\mu \mathrm{L}$ in multigravid women. The mean parasite count in Plasmodium falciparum parasitized subjects was $2650 \pm 234$ parasites $/ \mu \mathrm{L}, 95 \%$ confidence interval (2092-3118). Malaria parasite was found to exert a significant reduction in platelet density in parasitized subjects. This reduction was more pronounced in primigravidae and multigravidae. An inverse relationship was established between parasite density and platelet count $(\mathrm{y}=-0.020 \times+86.2, \mathrm{r}=-0.3)$.

Conclusion: There is need for a strengthened antenatal care system with increased awareness of the problem among communities most affected by malaria. Preventative strategies including regular chemoprophylaxis, intermittent preventative treatment with antimalarials and provision of insecticide-treated bed nets should be implemented as well as integration of malaria control tools with other health programmes targeted to pregnant women and newborns.

Keywords: thrombocytopenia, malaria, pregnancy, Niger Delta, Nigeria submit your manuscript | www.dovepress.com

Dovepress
Pathology and Laboratory Medicine International 20I0:2 I-5

(c) 2010 Erhabor et al, publisher and licensee Dove Medical Press Ltd. This is an Open Access article which permits unrestricted noncommercial use, provided the original work is properly cited. 


\section{Introduction}

Malaria in pregnancy is a major public health problem in endemic tropical and subtropical countries and a major cause of fetal and maternal morbidity and mortality. The prevalence of malaria in Africa has been increasing steadily causing around 10,000 deaths in each year. ${ }^{1}$

Malaria and pregnancy are mutually aggravating conditions. The physiological and pathological changes in pregnancy due to malaria have a synergistic effect on the course of each other. Pregnancy increases susceptibility to malaria and is associated with profound alterations in the coagulation systems. ${ }^{2}$ While normal pregnancy produces physiological changes, severe malaria caused by Plasmodium falciparum can cause profound thrombocytopenia. ${ }^{3}$ The possible mechanisms leading to thrombocytopenia in malaria includes: immune mechanisms, oxidative stress, alterations in splenic functions, and a direct interaction between plasmodium and platelets. ${ }^{4}$ Thrombocytopenia in pregnancy was defined by a platelet count lower than $100 \times 10^{9} / \mathrm{L}$. This is the value that falls two standard deviations below the mean platelet count in healthy Nigerian women reported from a previously published cohort study. ${ }^{5}$

There appear to be a dearth of information on the effect of P. parasitaemia on hematological parameters of infected pregnant women in the Niger Delta of Nigeria. The Niger Delta of Nigeria is said to be the world's largest wetland. These 36,000 square kilometers (14,000 square miles) of marshland, creeks, and tributaries and lagoons drain the Niger River into the Atlantic at the Bight of Biafra. Additionally transportation through this ecosystem, which is usually via rivers and creeks that snake through dense mosquito-infested swamps. There is a high incidence of malaria in the area. Indeed early European visitors to the area described it as the "white man's grave-yard' because of the high malaria-related mortality rate they experienced. This study was therefore aimed at evaluating the effect of plasmodia parasitemia on the platelet count of pregnant women in the Niger Delta of Nigeria.

\section{Materials and methods}

\section{Subjects, settings, and design}

Between June to September 2006, complete blood count (CBC) measurements results were evaluated for 50 malariapositive, 50 nonmalaria-positive pregnant women from their antenatal booking consultation and 50 nonpregnant women. The 50 nonparasitized pregnant and nonpregnant women all had a negative blood smear for malaria while the 50 malaria parasitized pregnant subjects had acute
P. falciparum infection were enrolled into this multicenter observational study. Five study centers were used for the collection of samples namely; Nigerian National Petroleum Company (NNPC) Clinic, University of Port Harcourt Teaching Hospital (UPTH), Braithwaite Memorial Hospital (BMH), Ogbunabali Health Center, and Department of Medical Laboratory Science, Rivers State University of Science and Technology, all in Port Harcourt the heart of the Niger Delta of Nigeria. Subjects were women of child-bearing age, median 25 years (range 18-45 years). Subjects who were aged 18 years and above and who showed clinical and laboratory evidence of malaria were enlisted into the study as test group while age-matched pregnant nonparasitized women and nonpregnant subjects who showed no clinical or laboratory evidence of malaria were used as controls. The Ethical approval was granted by our institutional ethical committee before the commencement of the study and written informed consents was received from the study participants.

Healthy women were defined as pregnant women without malaria or other febrile illness at booking consultation. Malaria parasitemia was defined by the presence of asexual forms of $P$. falciparum on quantitative buffy coat (QBC) malaria test and confirmed by microscopic examination of the peripheral blood in a pregnant women with elevation of temperature (aural $<37.5^{\circ} \mathrm{C}$ ), history of fever or any of the following symptoms: headache, dizziness, joint pain, anorexia, nausea, or spontaneous bleeding.

\section{Laboratory analysis Blood collection}

Blood samples were collected by venipuncture into ethylene diamine tetracetic acid (EDTA) anticoagulated tubes and used for the determination of complete blood count, and malaria testing using the $\mathrm{QBC}^{\mathrm{TM}}$ Autoread ${ }^{\mathrm{TM}}$ Plus centrifugal hematology and malaria analyzer (model 428576, 2006; QBC Diagnostics Inc, Philipsburg, PA, USA).

\section{Hematological analysis and malaria parasite detection}

Platelet count were measured by the $\mathrm{QBC}^{\mathrm{TM}}$ Autoread ${ }^{\mathrm{TM}}$ plus analyzer (QBC Diagnostics Inc) using venous blood. The QBC $^{\mathrm{TM}}$ Autoread ${ }^{\mathrm{TM}}$ plus Centrifugal Hematology System (QBC Diagnostics Inc) yields quantitative value from venous or capillary blood for hematocrit, hemoglobin, mean corpuscular hemoglobin concentration (MCHC), platelet count, white blood cell count, granulocyte count and percentage, and a combined lymphocyte/monocyte count and percentage. 
Table I Effect of malaria platelet counts of subjects

\begin{tabular}{llll}
\hline Parameter & $\begin{array}{l}\text { Plasmodium parasitized } \\
\text { pregnant women }\end{array}$ & $\begin{array}{l}\text { Nonparasitized pregnant } \\
\text { women }\end{array}$ & $\begin{array}{l}\text { Nonparasitized and } \\
\text { nonpregnant women }\end{array}$ \\
\hline $\begin{array}{l}\text { Platelet count } \times 10^{9} / \mathrm{L} \\
(\text { Mean } \pm \text { SD) }\end{array}$ & $111.3 \pm 9.3^{\mathrm{ab}}$ & $255.09 \pm 24.10$ & $270 \pm 51.5$ \\
\hline
\end{tabular}

Notes: aSignificant difference observed between malaria-infected and noninfected pregnant women $(P=0.05)$; 'bignificant difference observed between malaria infected pregnant women and nonpregnant control $(P=0.05)$; ${ }^{\circ}$ No significant difference observed between nonparasitized pregnant women and nonpregnant women. Abbreviation: SD, standard deviation.

Malaria diagnosis was made using the QBC malaria test. Fifty-five microliters of blood is taken in a QBC ${ }^{\text {TM }}$ tube coated with Acridine orange (AO) fluorescent dye and centrifuged for five minutes. The parasites in a QBC tube, when viewed with the Paralens microscope adaptor, are seen concentrated in the area below the Buffy Coat, fluorescing in the background of dark red blood cells (RBC). Blood smears (thin and thick films) were prepared for all QBC malaria-positive samples and stained with Giemsa stain (for confirmation, speciation, and parasite load determination) were read for 200 fields. Parasite counts were reported per 500 white blood cells (WBC) and for counts above 1,000 parasites per $500 \mathrm{WBC}$ by the percentage of infected RBC. All stages of the parasites were recorded (asexual and gametocytes). A previous study ${ }^{6}$ found diagnosis by direct centrifugation using $\mathrm{QBC}$ malaria to be at least eight times as sensitive as conventional microscopy when applied to serially diluted samples of malaria-infected blood. About $10 \%$ of infections diagnosed by direct centrifugal microscopy in a clinical setting were not detected by conventional examination of stained thick films. Superior sensitivity, together with the one step, solid state nature of the direct centrifugal procedure, provides important advantages for malaria diagnosis. Testing was carried out at the research laboratory in the Department of Medical Laboratory Science in the Rivers State University of Science and Technology, Port Harcourt.

\section{Statistical analysis}

Statistical analysis was analyzed using the Statistical Package for Social Sciences computer database (version 10; SPSS Inc., Chicago, IL, USA) to generate frequency distribution and percentage prevalence of the various parameters. Descriptive analysis of percentages of categorical variables was reported. Comparisons were assessed using mean and chi-square test. A $P$-value of $<0.05$ was considered statistically significant in all statistical comparison.

\section{Results \\ Effect of malaria platelets count}

The mean values, and standard deviations (Mean \pm SD) of the platelets count were significantly higher among nonpregnant and nonparasitized women compared to $P$. falciparum parasitized pregnant and nonparasitized pregnant women $\left(270 \pm 51.5 \times 10^{9} / \mathrm{L}, 255.09 \pm 24.10 \times 10^{9} / \mathrm{L}\right.$ and $111.3 \pm$ $\left.9.3 \times 10^{9} / \mathrm{L}\right)$ respectively $\left(\chi^{2}=81.00 ; P=0.01\right)$. The mean (SD) of parasite count of plasmodium parasitized subjects was 2650 (234). Forty-two of the 50 (84\%) malariaparasitized women were thrombocytopenic with platelet count $<100$ cells $\times 10^{9} / \mathrm{L}$.

\section{Effect of malaria and gravidae on platelets count}

Table 2 shows the mean platelet count and SD based on gravidae status. Platelet count values were $112.5 \pm 9.68 \times 10^{9} / \mathrm{L}$ and $126.3 \pm 16.7 \times 10^{9} / \mathrm{L}$ for the primigravidae and multigravidae, respectively. $\left(\chi^{2}=10.46 ; P=0.05\right)$. Parasite density was significantly higher among plasmodium parasitized primigravidae compared to multigravidae $2150(1638-2662)$ parasites $/ \mu \mathrm{L}$ in primigravidae women compared to $1826(1430-2222)$ parasites $/ \mu \mathrm{L}$ in multigravidae women. The mean parasite count in P. falciparum parasitized subjects was $2650 \pm 234$ parasites $/ \mu \mathrm{L}$, 95\% confidence interval (2092-3118). Malaria parasite was found to exert a significant reduction in platelet density in parasitized subjects. This reduction was more pronounced in primigravidae and multigravidae. An inverse relationship

Table 2 Effect of gravidae status on the platelet counts on malaria-infected women

\begin{tabular}{llll}
\hline Parameter & $\begin{array}{l}\text { Malaria parasitized primgravidae } \\
(\text { Mean } \pm \text { SD) }\end{array}$ & $\begin{array}{l}\text { Malaria parasitized multigravidae } \\
(\text { Mean } \pm \text { SD) }\end{array}$ & $\chi^{2}$ \\
\hline Platelet count $\left(\times 10^{9} / L\right)$ & $112.5 \pm 9.68^{\mathrm{a}}$ & $126.3 \pm 16.7$ & 10.46 \\
\hline
\end{tabular}

Notes: aSignificant difference observed between malaria-infected and noninfected pregnant women $(P=0.05)$.

Abbreviation: SD, standard deviation. 
was established between parasite density and platelet count $(y=-0.020 \times+86.2, r=-0.3)$.

\section{Discussion}

In this study carried out in the malaria endemic Niger Delta of Nigeria, we observed that the mean platelet counts $\left(\times 10^{9} / \mathrm{L}\right)$ were significantly lower in pregnant subjects with an episode of $P$. falciparum malaria compared to pregnant nonparasitized and nonpregnant and nonparasitized controls. This finding is consistent with previous reports which found thrombocytopenia a common occurrence in asymptomatic malaria infected women with $P$. falciparum $^{7,8}$ and $P$. vivax infection. ${ }^{9,10}$ Thrombocytopenia has also been reported in $P$. falciparum parasitized Nigerian children. ${ }^{11}$ The mechanisms leading to thrombocytopenia in malaria is thought to include immune mechanisms, oxidative stress, alterations in splenic functions, and a direct interaction between plasmodium and platelets. ${ }^{4}$ It is estimated that $40 \%$ of the world's pregnant women are exposed to malaria infection during pregnancy. The clinical features of $P$. falciparum malaria in pregnancy depend to a large extent on the immune status of the woman, which in turn is determined by her previous exposure to malaria. In pregnant women with little or no pre-existing immunity, such as women from nonendemic areas or travellers to malarious areas, infection is associated with high risks of severe disease with maternal and perinatal mortality. However adults who are long-term residents of areas of moderate or high malaria transmission, including large parts of sub-Saharan Africa, usually have a high level of immunity to malaria. ${ }^{12}$ Another important finding was that thrombocytopenia, although uncommon, was also seen in asymptomatic malaria infected women with $P$. falciparum. ${ }^{7}$ The observational data presented in this study is consistent with findings in previous studies in nonpregnant patients, that reduction in platelet count is associated with both falciparum and vivax malaria. ${ }^{11,13,14}$ In these cohorts, approximately one in five episodes of falciparum malaria and one in 20 episodes of vivax malaria were associated with significant thrombocytopenia. The weekly screening for malaria in the antenatal clinic setting ${ }^{14}$ is a very active process of case finding and it will often detect infection before women are symptomatic. This is unlike the standard case management method described by the World Health Organization as one of the interventions for control of malaria in pregnancy ${ }^{14}$ where women arrive to the clinic because they have symptoms and are treated. Women in the Niger Delta could benefit from a similar program. Reduced platelet counts during malaria infection result from platelet activation, splenic pooling, and a decreased platelet lifespan to 2-3 days (from normal 7-10 days). ${ }^{7,13}$ The role of immunological factors remains uncertain. However reduction in platelet count has been observed in a previous study to be directly proportional to disease severity, and that it recovers promptly with recovery from the infection. ${ }^{15}$ Pregnancy itself can also cause thrombocytopenia for reasons that are not fully understood. ${ }^{16}$ The rate of platelet recovery following initiation of treatment for malaria is reported variably as between 4 to 10 days but differs with the severity of malaria and antimalarial treatment prescribed. ${ }^{17}$

Our study shows that plasmodium falciparum-parasitized primigravidae seemed to be at a significantly greater risk of thrombocytopenia compared to multigravidae women. The mean parasite count in $P$. falciparum parasitized subjects was significantly higher in primgravidae compared to multigravidae. Plasmodium falciparum was found to exert a significant reduction in platelet count in parasitized subjects. An inverse relationship was established between parasite density and platelet count. This finding is consistent with previous studies ${ }^{18-20}$ in which placental parasite density and severity of plasmodium-induced thrombocytopenia was significantly more severe in primigravid women compared to secundigravid women.

Although the enormous burden imposed by malaria on infected individuals and the nation at large is huge and massive and costly eradication projects in highly endemic tropical countries undertaken in the past have proved unsuccessful, there is the need to support a major World Health Organization program to eradicate malaria tagged "roll-back malaria" that is presently going on in Nigeria. This program requires serious collective effort from relevant scientific researchers to enable the collection of locally generated public health data that could be of tremendous benefit. There is the urgent need for increased awareness of malaria among communities in the Niger Delta of Nigeria; integration of malaria control tools with other health programs targeted to pregnant women and newborns coupled with strengthened antenatal care systems and involvement of traditional birth attendants as part of health service delivery particularly because a significant number of women in the Niger Delta of Nigeria access antenatal care from these tradition birth attendants.

\section{Acknowledgments}

We thank the pregnant women who attended the antenatal clinics and the staff of the Nigerian National Petroleum (NNPC) Clinic, University of Port Harcourt Teaching Hospital (UPTH), Braithwaite Memorial Hospital (BMH), 
Ogbunabali Health Centre and Department of Medical Laboratory Science, Rivers State University of Science and Technology for their collaboration.

\section{References}

1. World Health Organization/United National International Children's Educational Fund. Africa Malaria report. WHO/CDS/MAL/2003.1093. Geneva, Switzerland: World Health Organization; 2003.

2. Franchini M. Haemostasis and pregnancy. Thromb Haemost. 2006;95:401-413.

3. Erhart LM, Yingyuen K, Chuanak N, et al. Hematologic and clinical indices of malaria in a semi-immune population of western Thailand. Am J Trop Med Hyg. 2004;70:8-14.

4. Rogerson SJ, Hvid L, Duffy PE, Leke RFG, Taylor DW. Malaria in pregnancy: pathogenesis and immunity. Lancet Infect Dis. 2007;7:105-117.

5. Essien EM, Usanga EA, Ayeni O. The normal platelet count and platelet factor 3. Availability in some Nigerian population groups. Scand J Haematol. 1973;10:378-383.

6. Spielman A, Perrone JB, Teklehaimanot A, Balcha F, Wardlaw SC, Levine RA. Malaria diagnosis by direct observation of centrifuged samples of blood. Am J Trop Med Hyg. 1988;39:337-342.

7. Abdalla S, Pasvol G. Platelets and blood coagulation in human malaria. In: Newton PN, Essien E, White NJ, editors. The Haematology of Malaria. London, UK: Imperial College Press; 2004. pp. 249-276.

8. Tan SO, McGready R, Zwang J, et al. Thrombocytopenia in pregnant women with malaria on the Thai-Burmese border. Malar $J$. 2008;7:209.

9. Kreil A, Wenisch C, Brittenham G, Looareesuwan S, Peck-Radosavljevic M. Thrombopoietin in Plasmodium falciparum malaria. Br J Haematol. 2000; 109:534-536.
10. Kumar AS. Thrombocytopenia-an indicator of acute vivax malaria. Indian J Pathol Microbiol. 2006;49(4):505-508.

11. Jeremiah ZA, Uko EK. Depression of platelet counts in apparently healthy children with asymptomatic malaria infection in a Nigerian metropolitan city. Platelets. 2007;18:469-471.

12. Ofori M, Ansah E, Agyepong I, Ofori-Adjei D, Hviid L, Akanmori B. Pregnancy-associated malaria in a rural community of Ghana. Ghana Med J. 2009;43:13-18.

13. Beale PJ, Cormack JD, Oldrey TB. Thrombocytopenia in malaria with immunoglobulin (IgM) changes. Br Med J. 1972;1:345-349.

14. Richards MW, Behrens RH, Doherty JF. Short report: hematologic changes in acute, imported Plasmodium falciparum malaria. Am J Trop Med Hyg. 1998;59:859.

15. Hemmer CJ, Kern P, Holst FG, Nawroth PP, Dietrich M. Neither heparin nor acetylsalicylic acid influence the clinical course in human Plasmodium falciparum malaria: a prospective randomized study. $\mathrm{Am}$ J Trop Med Hyg. 1991;45:608-612.

16. Boehlen F. Thrombocytopenia during pregnancy. Importance, diagnosis and management. Hamostaseologie. 2006;26:72-74.

17. Kreil A, Wenisch C, Brittenham G, Looareesuwan S, Peck-Radosavljevic M. Thrombopoietin in Plasmodium falciparum malaria. Br J Haematol. 2000;109:534-536.

18. Nosten F, Ter Kuile F, Maelankirri L, Decludt B, White NJ. Malaria during pregnancy in an area of unstable endemicity. Trans $R$ Soc Trop Med Hyg. 1991;85:424-429.

19. Kabanywanyi AM, Macarthur JR, Stolk WA, et al. Malaria in pregnant women in an area with sustained high coverage of insecticide-treated bed nets. Malar J. 2008;7:133.

20. Desai M, Ter Kuile FO, Nosten F, et al. Epidemiology and burden of malaria in pregnancy. Lancet Infect Dis. 2007;7:93-104.
Pathology and Laboratory Medicine International

\section{Publish your work in this journal}

Pathology and Laboratory Medicine International is a peer-reviewed open access journal focusing on innovative basic research and translational research related to pathology or human disease. The journal includes original research, updates, case reports, reviews and commentaries on current controversies. The Academic Sponsor

\section{Dovepress}

of this journal is the Chinese American Pathology Association (CAPA). The manuscript management system is completely online and includes a very quick and fair peer-review system. Visit http://www.dovepress.com/testimonials.php to read real quotes from published authors.

Submit your manuscript here: http://www.dovepress.com/pathology-and-laboratory-medicine-international-journal 